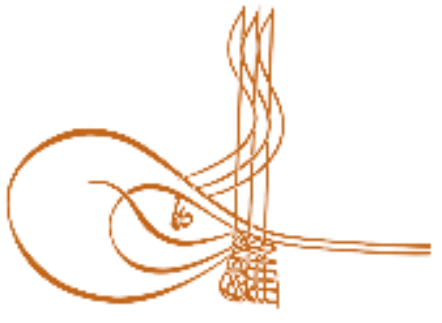

www.turkishstudies.net/social
Turkish Studies - Social Sciences

eISSN: $2667-5617$

Research Article / Araştırma Makalesi

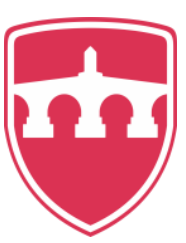

INTERNATIONAL

BALKAN

UNIVERSITY

Sponsored by IBU

\title{
Futbolda Hakem ve Video Hakem 'VAR' Sisteminin Weber'in Rasyonalite Teorisi İle Açıklanması ve Post-Modern Görüşler
}

\author{
The Explanation of Referee and Video Assisted Referee 'Var' System Through the Weberrian \\ Perspective of Rationality and Post-Modern Theories
}

\author{
Barış Şentuna*
}

\begin{abstract}
Football both in Turkey and in world is at the state of a loved sports branch. The style of football game, both attracts individual and society. Like every game, the need for someone who knows the rules and guarantees the obedience, creates the referee as authority. The resource of authority in football is referee. Referee rules the game and has the power to change the game. When we think of classification of rationality and authority the first name who did this is Max Weber. The decisions of referee and its resemblances with Weber's rationality types, the affect of VAR system to the rationality of referee are discussed in this paper. Referee takes his/her source of authority from book of rules and laws. From this point of view, referee can be classified under legal-rational authority. In this study in addition to Weber's authority types, his rationality system is considered, the difference between the types of rationality of both referee and spectators are analyzed. In this analysis the referees formal rationality and spectators substantive rationality are found to be contradicting, and this contradiction reveals itself more by the improvement of technology. From this perspective the shift to VAR becomes inevitable. In addition to this, post-modern theorists Foucault and Deleuze's thoughts are considered and discussed in this paper. Based on Foucault's panopticon term referee is under watch all the times. This watching affects football in a positive way. For Deleuze shift from discipline society to control society accelerated. In this sense, VAR increases the control in football. Although the increase in control seems to have advantages from many ways, we must keep in mind that it can also lead to some unwanted conclusions.
\end{abstract}

Structured Abstract: Football both in Turkey and in world is at the state of a loved sports branch which has become the most popular sport even above countries. The number of countries registered to United Nations (UN) is 193 where as to World Football Federation (FIFA) is 211. Referee has always been one of the most important part of football. Various academic studies are made on referee and his decisions. One aim of philosophy and sociology is to give direction to the academic world through analyzing concepts. The aim of this study is to give new insights on the relatively new concept Video Assisted Referee (VAR). This paper tries to do this by focusing on decisions of referee and showing its resemblances with Weber's rationality types. Throughout the paper the affect of Video Assisted Referee (VAR) system on the rationality of referee is

\footnotetext{
* Dr. Öğr. Üyesi, Balıkesir Üniversitesi, Fen-Edebiyat Fakültesi, Sosyoloji Bölümü Asst. Prof. Dr. Balikesir University, Faculty of Science and Letters, Department of Sociology ORCID 0000-0001-9982-8382

ejderkelebek@gmail.com

Cite as/ Atıf: Şentuna, B. (2020). Futbolda hakem ve video hakem 'VAR' sisteminin Weber'in rasyonalite teorisi ile açıklanması ve post-modern görüşler, Turkish Studies - Social, 15(3), 1527-1540. https://dx.doi.org/10.29228/TurkishStudies.40530

Received/Geliş: 13 January/Ocak 2020

Accepted/Kabul: 25 April/Nisan 2020

Copyright $($ INTAC LTD, Turkey 
discussed and the difference between the decisions of referee and spectators is explained through Weber's rationality, together with post-modern theorists Foucault and Deleuze's thoughts in this paper.

In its glossary meaning referee is the person consulted to solve a disagreement. In football referee also have the power to administrate the game. It is very hard to give decision within seconds that can affect the result of the game and not to remain in "aporia" an ancient greek term which means undecidability. Referee is the absolute ruler of the game with authority. In symbolic meaning it is the case as well. In formal matches, the referee comes to the pitch with the ball and leaves the pitch with the ball, where without ball there cannot be any football at all. In FIFA's rules of the game book, the referee is defined as the person who has "absolute authority". The role of the referee is to ensure the rules of the game are followed. It is to ensure what Wittgenstein calls "rule following". This situation definetly creates a tension on the referee. It is even used by media and there are television programs hours long which discuss the decisions of referee.

Weber is one of the dominant figures of social theory, re-interpreted the concept of authority through Nietszchian perspective. In its simplest form by Szelényi; Weber's theory is "domination (authority) = power + legitimacy". This formulation defines referee. Referee takes his/her power from rule book and its legitimacy from formality. There is no referee in street child football or recreational football. In Turkish legislation and law, it is clearly defined that any progressive action taken against referee are punished as against state officer under active duty. Although football federation in Turkey like many other countries is self-governing.

Weber's types of authority are: traditional authority, charismatic authority, legal-rational- authority. Legal-rational authority fits the football referee. In legal rational authority there are legal rules and to obey to the people's orders who apply these rules. People obey these rules because they believe the superiority of laws. In reality the obedience is not to the persons but rather to the law. This is expected by the spectators of football. In others words the appliance of the laws without taking a side. In that sense the main authorities designing the football decided on the video assisted referee (VAR) to prevent the social disagreements on referee.

In some parts of society the shift to rationality is fast but in some parts it is relatively slow. Although some football authorities defend VAR will disturb the nature of football, rationally wins the disagreement. By the improvement of technology which allows spectators watching the controversial positions in front of televisions giving decisions through substantive rationality, conflicts with referees decisions through formal rationality. This starts to put football capital into risk and made the shift to VAR more faster and necessary.

Another concept by Weber important for us here is rationality as it plays an important role in giving decisions. Weber's types of rationality are, practical rationality, theoretical rationality, substantive rationality and formal rationality. The bureaucratic authority and power lead to formal rationality. Referee while giving decisions is in this type of rationality. For substantive rationality Weber gives the example of friendship. It covers only some part of life practices. When there is friendship there comes the values loyalty, two way harmony and those make up substantive rationality. Calvinism, socialism, budism, even look to beauty in the same way creates substantive rationality. The supporters in favor of a club in football is this type of rationality. Where referee is under formal rationality supporters are under substantive rationality. This conflict is the summary of Western society in general. In that sense the emergence of VAR is major step to prevent this conflict.

The formal definition of VAR includes its aim is not to intervene all positions, the minimum intervention with maximum efficiency. There are few studies that support referees also want VAR system. Where as although lack of academic studies some data groups like Good Form say fans \%96 per cent agree that referee decisions are mistaken. Although with VAR the discussion still continues because it is still in referee's decision to go to VAR; the coaches or footballer's cannot not ask for VAR revision. The ultimate decision is still on the referee. Although the traditional referee is under attack. In near future it is expected to intervene much more by the development of technologies.

When we shift to post-modern theories Foucault's concept of panopticon is important in that sense. The concept of panopticon is you are being watched in your every movement but you do not see the the watcher. This has a positive affect on the referee. Although there are studies that they give more extra time to the home team etc. This also brings us to another post-modern thinker Deleuze. For Deleuze the societies of discipline are replacing with societies of control. In today's world, the football spectators are not the only ones in the stadium but the huge amount is the spectators watching in their homes with $4 \mathrm{~K}$ televisions. They also create a very big economic capital that Barcelona's \%37 of income is from broadcasting income. These spectators are

Turkish Studies - Social, 15(3) 
in hyper-reality that they can see every detail, every replay where as the referee cannot. This leaves the traditional referee giving formal decisions defenseless.

One counter argument to these arguments can be joy of football comes from the ambiguity of the result including referee decisions; that a small club can win against a big club. This tendency is becoming lower as the clubs start to earn millions of dollars. On the other hand this is not the fault of referee but rather capitalism and football's turning into a giant economy. In the data presented by Good Form group \%54 of fans take joy from arguing on the referee's decisions. Football, in big picture is entertainment and entertainment is very hard to define that can include arguing, tension and joy all together.

Keywords: Football, Football Referee, Rationality, Max Weber, Video Assisted Referee (VAR).

Öz: Futbol gerek Türkiye'de gerekse dünyada çok sevilen bir spor dalı konumundadır. Futbolun oyun tarzı, hem bireyin hem de toplumun ilgisini çekmektedir. Her oyunda olduğu gibi, bu oyunun da kurallara hâkim bir bilirkişi tarafından yönetilmesi ihtiyacı otorite kavramını doğurmuştur. Futbolun otorite kaynağı da hakemdir. Hakem, oyunu yöneten ve oyunun gidişatını şekillendiren kişidir. Otorite ve rasyonalite kavramlarının toplumsal sınıflamasını yapan ilk kişi ise Max Weber'dir. Hakemin kararlarının, Weber'in rasyonalite tipleriyle gösterdiği benzerlikler ve futbol hakeminin rasyonalitesine VAR sisteminin etkisi bu makalede tartışılmıştır. Hakem, otoritesinin kaynağını kural kitabından ve yasalardan alır. Bu anlamda hakem, yasalussal otorite tiplemesine girer. Bu çalışmada, Weber'in otorite tiplemelerine ek olarak rasyonalite sistemi de ele alınmakta ve bu doğrultuda VAR sisteminin hakemin rasyonalitesine etkisi ve taraftar görüşleri ile hakemin görüşleri arasındaki fark incelenmektedir. $\mathrm{Bu}$ incelemede hakemin formal rasyonelliği ile taraftarların substansif rasyonelliğinin birbirleriyle çeliştiği, gelişen teknoloji ile bu çelişkinin daha çok ortaya çıktığı görülmektedir. $\mathrm{Bu}$ anlamda VAR sistemine geçiş kaçınılmaz olmuştur. Buna ek olarak post-modern teorisyenler olan Fouccault ve Deleuze'un görüşleri de Weber' in devamı niteliğinde ele alınarak tartışılmıştır. Foucault'un panoptikon kavramı ile hakem sürekli izlenir durumdadır. Bu izlenme futbolu pozitif etkilemekiştir. Deleuze'e göre ise disiplin toplumlarından denetim toplumlarına geçiş hızlanmıştır. Bu anlamda da VAR futbolda denetimi arttırmaktadır. Fakat denetimin artması birçok açıdan avantajlı gibi görünmesine rağmen, bazı istenmeyen durumların oluşabileceği de göz ardı edilmemelidir.

Anahtar Kelimeler: Futbol, Futbol Hakemi, Rasyonalite, Max Weber, Video Yardımcı Hakem (VAR).

\section{Giriş}

Futbol, hem Türkiye'de hem dünyada, "ayak topu" anlamında bir oyun olmaktan fazlasını ifade etmektedir. Küresel popülerliği oldukça fazla olan bu oyun türü, bireylerin ve dolayısıyla içinde bulunduğumuz toplumun bir parçası haline gelmiştir. Futbolun dünya çapında var olan sarsılmaz mevcudiyeti; futbolun bir oyundan fazlası olduğunu, bireylerde bir yaşam tarzı olarak ifade edilmesini de beraberinde getirmektedir. Toplumsal alanda büyük bir yer edinen bu oyun, bilimsel açıdan özellikle de sosyolojik olarak incelenmeye değerdir. Bu çalışma, futbolu Türkiye'de belki de en çok tartışılan yönü ile yani hakem açısından incelemek için yazılmıştır. Video hakem (VAR) sisteminin devreye girmesi ile birlikte oyunun etrafinda gelişen sosyolojik ve felsefi arka boyutu ortaya çıkarmak, bu makalenin öncelikli amacıdır.

Futbolda hakem, yüzyıllardır oyunun en önemli parçalarından bir tanesi olmuștur. Hakemin verdiği kararlar zaman zaman eleştirilmiş, zaman zaman televizyon programlarının önemli bir bölümünde yer bulmuştur. Hakem kararlarını etkileyen faktörler üzerine çeşitli araştırmalar yapılmıştır. "Ingiltere'de yapılan bir araştırmada hakem kararlarının ev sahibi takımlar lehine olduğu ortaya çıkmıștır." (Boyko, 2007: 1185-1194) Benzer araștırmalarda hakemin kararlarının seyircilerin seslerinden etkilendiği de ortaya konulmuştur (Satman, 2014: 147-154). Türkiye'de hakemlerin genel durumu üzerine benzer çalışmalar yapılmış ve hakemlerin fiziksel düzeylerine (Can ve diğerleri, 2016: 23-40), geçmiş yaşantılarına, medyayı takip edip etmediklerine göre kararlarının etkilenip etkilenmediği (Önür ve diğerleri, 2015: 392-410) ç̧şitli şekillerde 
araştırılmıştır. Bu bilimsel makaleler, hakemin kararının bilimin bir konusu olabileceğini ve bunun çeşitli yöntemler ile araştırılabileceğini bize göstermektedir.

Sosyolojinin ve felsefenin asli görevlerinden bir tanesi, çeşitli sorular sorarak bilimsel çalışmalara yön vermek, yeni araştırma konuları ortaya koymaktır. Özellikle hayatımıza giren yeni teknolojiler üzerinde günümüz felsefecileri ( bkz. Chalmers, Žižek ) bu konularda araştırma yapacak bilim adamları için çeşitli fikirler üretmektedirler. Bu makalede ise VAR sistemi üzerine sunulan görüşler, Weber'in otorite tiplemeleri ile değerlendirilmiş, hakemin geleceğine ve algılanışına dair bir düşünce yapısı oluşturulmaya çalışılmıştır.

\section{Futbol ve Futbolda Hakemin Yeri ve Otoritesi}

Günümüzde futboldan daha evrensel bir spor yoktur. Bu spora dünya çapında direnen bölge yok denecek kadar azdır. Futbol, mevcut konumunu zorla veya dayatmalarla değil; toplumların daveti üzerine edinmiştir. Yapılan bu davet sonrasında, futbol yalnızca spor olarak kalmamış; ulaştığı kitleleri de futbola bağlamıştır. Öyle ki futbol ulusları aşmayı başarmıştır. Dünyada Birleşmiş Milletler'e kayıtlı ülke sayıs1 193 iken, FIFA'ya kayıtlı ulus sayısı 211'dir. Futbolun gücü, ulus olmanın önüne geçmiştir. "Futbol artık günümüzde karşı konulmaz bir fenomen olarak ön plana çıkmıştır. Kıtalardan ülkelere, gruplardan bireylere, ekonomiden kültüre, teknolojiye kadar birçok alanı etkilemekte ve birçok alandan etkilenmektedir" (Çakmak ve diğerleri, 2017, 127). Bu anlamda futbol oldukça iç içe geçmiş, karmaşık bir yapıyı ve sosyolojik unsurları da beraberinde getirmiştir. $\mathrm{Bu}$ makalede bu bütünün tümü yerine, parçalardan sadece bir tanesi olan hakem incelenmektedir.

Hakem sözcüğü Arapça kökenlidir ve "yargıç” anlamına gelmektedir. Dilimizde ise TDK'ye göre;

1. Tarafların aralarındaki anlaşmazlığı çözmek için yetkili olarak seçtikleri ve üzerinde anlaştıkları kişi, yargıcı.

2. Belirli bir konudan iyi anlayan kimse.

3. Seçme ve karar verme yetkisi bulunan kimse.

4. Spor karşılaşmalarını, yarışmaları kurallara uygun ve yansız olarak yöneten kimse anlamlarına gelmektedir.

Yani hakem, bir anlaşmazlığ 1 çözmek için iki tarafın başvurduğu kimse ya da kendisine seçme yetkisi verilen bilirkişi anlamına gelmektedir. Futbolda hakem, oyunu yöneten ve oyunda yönetme yetkisi olan bir isimdir. Bu yüzden önemli bir spor dalı olan futbolda hakemin yeri, en az futbolun kendisi kadar önemlidir.

Hakem olmanın ve hakemliğin zorlukları ortadadır. "Olayın farkına varan hakem çok kısa bir zaman dilimi içerisinde karar vermek durumundadır" (Cel, 1994). Özellikle felsefedeki "phronesis" kavramı bu anlamda çok önemlidir. Phronesis kelime anlamı olarak pratik bilgi ve erdemin en üst seviyesini ifade etmektedir. (Lawrence, Becker \& Becker) Hızlı ve doğru karar almak ve "aporia" adı verilen karar verememe durumunda kalmamak, son derece zor bir iştir. Bu nedenle hakemin yaşadığı psikolojik yoğunluk ve baskı üzerine birçok çalışma yapılmıştır.

Hakem maçın mutlak hâkimidir. Bu resmen böyledir, aynı zamanda sembolik olarak da bunu dünya spor tarihinde görebiliriz. Hakem oyuna elinde, oyunun temel nesnesi olan top ile gelir. Oyunun bitiminde de oyunun temel nesnesi olan topu alıp sahadan ayrilır. Bunun sembolik anlamı son derece derindir. Futbol müsabakası hakemle başlar ve yine hakemle biter. Bunun yanı sıra hakem adeta elinde İncil tutan bir papaza benzetilebilir. Kendisine yol gösterici olarak verilen kitabın kurallarının uygulanması için orada, oyundadır.

Futbol ile ilgili ilk resmi başvuru kaynağı, FIFA tarafından yayınlanan oyun kuralları kitabıdır. Bu kitapta Kanunlar (Laws) başlıkları altında; top, sahanın büyüklüğg̈ gibi kurallardan 
bahsedildikten sonra gelen 5. kanun, hakem üzerinedir. İlginçtir ki hakem üzerine yazılmış olan bölüm, tam da bu makalede tartışacağımız şekilde yani otorite ile başlar: "Tüm maçlar o maça atanmış hakem tarafindan yönetilir. Oyunun yöneticisi konumundaki hakem, maç ile ilgili olarak kuralların uygulanmasinda ve bu kurallara yönelik karar almada tam otorite sahibidir" ( FIFA, Oyun Kuralları, 1).

Buradaki en önemli mesele olan kuralların uygulanması, ünlü filozof Wittgenstein tarafından açıklanmıştır. Hakemin rolü, Wittgenstein'ın “kural takibi” adını verdiği şeyin uygulanmasıdır. Hakemin en önemli rolü budur. Hakem kuralları takip etse de oyunda oldukça yüksek bir otorite sahibidir. Bu konuda, acaba sakatlıkların sebebi hakemler mi şeklinde araştırmalar yapanlar dahi olmuştur. (Andersen, 2004) Şüphesiz hakemin bu anlamda niyeti son derece önemlidir. Bu niyet, açık ve net bir şekilde görülmese dahi, zaman zaman hakemin anlık kararlarını etkileyebilir.

Öte yandan pek çok meslekte psikolojik baskı söz konusudur. Bu psikolojik baskının "otorite" kaynaklı olabileceği üzerine bugüne kadar herhangi bir çalışma yapılmamıştır. Hakemin mutlak otoritesi, Weberci anlamda "rasyonel-ussal" otoritesi, pek çok tartışmayı da beraberinde getirmektedir. Bu durum medya tarafindan kullanılmakta, çok kısa bir zaman aralığında kesin karar vermek durumunda olan hakemin kararları, eski hakemlerin konuk olduğu saatlerce süren televizyon programları ile tartışılmaya ve kendi alanında bir sektör oluşturmaya başlamıştır. Bu bağlamda sonraki bölümde Max Weber'in otorite tiplemeleri ile rasyonellik kavramları ve çeşitleri incelenecektir.

\section{Max Weber, Otorite, Rasyonalite ve Hakem}

Sosyal teoride Weber'in yerine göz atacak olursak; Marx, Nietszche ve Freud gibi sosyal teorinin en önemli isimlerinden bir tanesi de Max Weber'dir. Marx ekonomik belirlenilmişliğin önemini ve düşünceler üzerindeki etkisini anlatırken, Freud bastırılmış fikirler üzerinde, medeniyet ve bastırma üzerinde durmuşlardır. Bu iki önemli isim daha çok kişinin deneyimi üzerine yoğunlaşırken; Nietzsche ve Weber, iktidar ve otorite üzerine yoğunlaşmıştır. Marx’ta ekonomi, Freud'da cinsellik ön plandayken Nietzsche ve Weber, özellikle güç ve otoriteyi teorilerinin temel noktasına koymuşlardır. Bunun yanı sıra ileride bahsedeceğimiz Fouccault otorite ve iktidar kavramlarını felsefesinin temeline oturmuştur. Son olarak da günümüz filozoflarından Baudrillard, daha karamsar bir tablo çizmiş, günümüzün değişen hiper-gerçek dünyasının Nietzsche'ci yorumlamasını yapmıştır. Otorite üzerine Nietzsche bunu en radikal ve provokatif haliyle yaparken, Weber (1864-19219) daha 1lımlı anlamda ruhun otorite altında kaldığını ve baskılandığını düşünmüştür.

Protestan bir aileden gelen Weber, Doğu Almanya'da doğmuş, 1896 yılında Heidelberg üniversitesine politika üzerine profesör olarak atanmıştır. 1913-1919 yılları arasında din üzerine yazmış, 1914-1920 arsında ekonomi ve toplum üzerine yazmış, en önemli kitaplarından bir tanesi olan Opus Magnum'u bitiremeden 1920 yılında vefat etmiştir.

Weber, Nietzsche'nin bakış açısıyla iktidar kavramını tekrar yorumlamıştır. En genel anlamıyla: "İktidar kavramı, siyasal, toplumsal, ekonomik, vb. yönleri olan çok geniş bir anlam yelpazesine sahip olup, bir kimsenin veya bir grubun diğerlerini kontrol edebilme kapasitesini anlatmaktadır" (Özdemir, 2014, 72). En basit anlamıyla Weber'de formülize edecek olursak "güç + meşruiyet $=$ otorite" şeklinde bir formül karşımıza çıkar. (Szelényi, 2011)

Szelényi'nin bu formülü tam olarak hakemi karşımıza çıkarır. Hakem gücünü kural kitabından alır, meşruiyetini ise resmiyetinden alır. Resmi olmayan maçlarda özel bir durum olmadıkça hakem bulunmaz. Çocukların sokakta kendi aralarında yaptıkları maçlarında, insanların rekreasyon aktivitesi olarak yaptıkları halı saha maçlarında hakem yoktur. Futbol federasyonu, özerk bir yapıya sahiptir. Futbol kulüpleri ise özel iktisadi işletmelerdir. Fakat hakem, resmi olarak Türk Ceza Kanunu'nda kamu görevlisi olarak geçmektedir. 
Spor müsabakalarında oluşabilecek yaralanmalar "kabul edilen risk" kavramı ile açıklanırken (Özocak, 2018, s.92) hakeme karşı işlenebilecek yaralama suçları kamu görevlisine karşı işlenmiş suçlar kapsamında değerlendirilir. "6222 sy. Kanun m. 20 uyarınca hakemler yapmış olduklarl görev nedeniyle kamu görevlisi sayıldıklarından, hakemlere karşı işlenen kasten yaralama suçu TCK m. 86/3 (c) uyarınca "kişinin yerine getirdiği kamu görevi nedeniyle" işlenen yaralama suçu olup faile verilecek ceza ağırlaştırllmaktadır." (Yargıtay 4. CD, 21.01.2015, 2014/31271 E. ve 2015/1793 K) (Hürmüz, 2016, s. 100.) Bu anlamda hakem kural kitabının yanı sıra kamu adına sahada bulunmaktadır.

Weber, "Toplum ve Ekonomi” kitabında meşru otoritenin türlerini üç ana başlık altında toplamıştır. Bunlar; geleneksel, rasyonel ve karizmatik otoritedir. Klasik hakem modeli ve video hakem açısından bu üç başlık içinden geleneksel ve rasyonel olanla ilgilenmemiz daha uygun olacaktır. Yine de üç başlığın kısaca tanımları şöyledir:

"Rasyonel temeller - yasallaştırılmış kuralların ve bu tür kurallara göre otorite konumuna yükselmiş olanların emirler yayınlama hakkının yasallığına olan inanca dayanırlar.

Geleneksel temeller - çok eski geleneklerin kutsallığına duyulan yerleşmiş inanca ve onların altında uygulanan otoritenin meşruluğuna dayanırlar.

Karizmatik temeller - tekil bir kişinin ve onun tarafindan buyurulan ya da ortaya çıartılan normatif kalıpların ya da düzenin istisnai kutsallığına, kahramanlığına ya da örnek gösterilen karakterine bağlılığa dayanabilir" (Weber, 2012).

Yasal-rasyonel otoritede yasallaştırılmış kurallar ve o kurallar doğrultusunda otorite konumuna atfedilmiş kişilerin emirlerine uyma inancı vardır. Meşruluğu, akılcı ilkelere göre oluşturulmuş kanunlara dayanmaktadır. Tıpkı hakem örneğinde olduğu gibi, gücünü kanunların çizdiği sınırlara göre uygulamaktadır. Kişiler kanunların üstünlüğüne inandıkları için yasalar dolayısıyla oluşturulmuş rasyonel otoritenin meşruluğuna itaat ederler. Aslında mevcut olan otoriteye değil, kurallara itaat vardır. "Rasyonel-yasal otorite türünde kişi, otoriteye itaati yürürlükteki kuralların yasallı̆̆ ve bu kurallar gereğince otorite konumuna yükselenlerin buyruk verme haklarının olduğuna inandiğı için kabul eder" (Uzdu, 2016: 71). Öte yandan meşruiyetini ve gücünü kanunlardan alan hakem, mutlak dokunulmazlık sahibidir. Bu anlamda hakem geleneksel otoritenin tam temsili konumundadır fakat kanunların akılcılığı vasıtası ile rasyonel otoritenin de temsili olabilecek konumdadır. Bu tam da futbolda istenen esas şeydir. Başka bir deyişle, sadece kuralların tarafsız bir şekilde uygulanması günümüz seyircisinin ve taraftarının tek isteği haline gelmiştir. Bu kısım makalenin ana unsurunu oluşturmaktadır. Öyle ki hakem konusunda toplumsal anlaşmazlıklar ortaya çıkmaması için futbolu yöneten otoriteler tarafından düzenlenen video hakem (VAR), bu ussal konumu ve rasyonelliği tekrar tesis etmek için getirilmiştir.

Günümüzün ruhu akılcılığa dayanmaktadır. Aklen üstün olan, bizlere üstün gelen, geleneksel olanın yerini alıp onu değiştirme eğilimi uyandırmaktadır. Bu durum adeta bir medeniyet göstergesi olarak karşımıza çıkar. Toplumun bazı alanlarında rasyonelliğe geçiş hızlı olurken, futbol gibi bazı kemikleşmiş kuralları olan alanlarda bu geçiş zaman almış ve almaktadır. Dönemin TFF başkanı video hakem uygulmasına karşı olduğunu, futbolun doğasını bozacağını açılasa da (Fotomaç, 12.10.2017) rasyonellik galip gelmiştir. Bu geçişi oyunun doğasını bozmadan sağlamak için yeni teknolojilere yapılan yatırım, kapitalin büyümesi ile kaçınılmaz hale gelmiştir. Televizyonlarından tekrarları ve tartışmalı pozisyonları izleyen taraftarların substansif rasyonellik gereği, yanlış formal rasyonel hakem kararları ile çelişmesi ve bu çelişkinin her anlamda futbol kapitalini tehlikeye atar hale gelmesi ile birlikte, futbol özelinde VAR sistemine geçişin yolu açılmıştır. VAR bu anlamda sadece bir teknoloji değil; aynı zamanda da olası bir otorite ve rasyonellik değişimini beraberinde getiren bir sistem olmuştur. Fakat her değişim gibi bu değişimin de kendi içinde sancıları ve dirençleri vardır. 
$\mathrm{Bu}$ noktada Weber üzerine kısaca değinilmesi gereken bir başka husus bu rasyonelliktir. $\mathrm{Bu}$ rasyonellik ve çeşidi hakem üzerine çıkan tartışmaların kaynağı konumundadır. $\mathrm{Bu}$ anlamda Weber'in rasyonellik kavramlarını kısaca özetlemek yerinde olacaktır.

Weber'de rasyonellik ve rasyonalizasyon çeşitleri dört tanedir. Pratik, teorik, substantif ve formal rasyonellik:

1. Pratik rasyonellik: Weber kişinin tamamen faydacı ve egoist yaklaşımıyla bakış açısını, yargılamalarını, gündelik aktivitelerinde kullandığ 1 rayonellik biçime "pratik rasyonellik" der (Weber, 1930, 1958a, s. 77).

2. Teorik rasyonellik: Bu tip rasyonellik eylem yerine artan bir kesinlikle tamamen soyut kavramlar ve gerçeklik üzerinde bilinçli ustalık gerektirir. Daha genel olarak tüm soyut bilişsel süreçler, tüm uzanımları, teorik rasyonelliği oluşturur (Weber, 1946, s. 293).

3. Substansif rasyonellik: Bu tip rasyonellik pratik rasyonelliğe benzer ama teorik rasyonelliğin zıttıdır. Eylemlerin davarnış biçimleri modelleri halinde uygulanmasıdır. Sadece sebep-sonuç ilişkileri üzerinde durmaz, rutin problemler üzerine çözümler üretmez, aynı zamanda geçmiş, şimdiki zamandaki veya potansiyel değerler üzerinden çalışır (Weber, 1968, ss. 85-86).

4. Formal rasyonellik: Pratik, teorik ve substansif rasyonelliğin medeniyetler üstü karakterinin aksine formal rasyonellik endüstrileşme ile birlikte başlayan, yaşam şekilleri üzerindeki kanuni, ekonomik, bilimsel alanlarda bürokratik otoritenin etkisi ile oluşur (Kalberg, 2010, s.1158).

Weber bürokratik otorite ve güce, formal olarak rasyonel der. Çünkü eylemleri akıl tarafindan genellenebilen kurallar ve statüler burada ön tahakkümlerini kurarlar ve bunların uygulanması için en uygun araçları kullanırlar. Başka bir deyişle en rasyonel tahakküm bürokrasinin içindedir (Weber 1968, s. 226, s. 975, 1946 s.295). Hakem bu bürokrasinin tam da ortasındadır. Hem oyuna en yakın müdahale şansı olan ve otorite kurabilen hem de üzerindeki Merkez Hakem Kurulu tarafından maçlara atanması ile otorite kurulan konumundadır. Eski en üst düzey hakem ve spor yorumcularından Ahmet Çakar tahakkümün boyutunu, sosyal boyutunu ve olası yanlışlıklar ile neler olabileceğini bir yazısında şöyle ifade eder: "Merkez Hakem Komitesi... pek tabii XX'i (yazarın ad değisstirmesi) verdiler ve hiç risk almadılar. Bu demek değildir ki cumartesi günü XX mükemmel maç yönetir. Bu işler kolay değil. Çalacağın veya çalmayacağın bir düdük, bırakın skoru değiştirmeyi, toplumsal bir olaya bile neden olabilir" (Çakar, Sabah, 29.09.2019).

Substansif gerçeklik için hayatın belirli bir alanını kapsadığı ve diğer kalanını dokunulmamış bıraktığ 1 söylenebilir. Buna Weber örnek olarak "arkadaşlığı" verir. Arkadaşlık oluştuğunda beraberinde sadakat, merhamet, karşılıklı uyumluluk gibi değerleri beraberinde getirir ve bunlar bir substansif rasyonellik oluşturur. Komünizm, feodalizm, hedonizm, Kalvinzim, sosyalizm, Budizm, Rönesans bakış açısı, hatta estetik olarak güzelliğe bakış açısı da substansif rasyonelliği beraberinde getirir, tabi ki bunlar beraberinde çeşitlilik ve çelişkiyi de organize ettikleri eylemler ve değerlerinin içerikleri oranında içerebilirler (Weber, 1968, ss. 44-45). Bu anlamda taraftarlık (bir takımı tutan kişilerin birlikteliği) de bu tip bir substansif rasyonelliği oluşturduğu açıktır.

Taraftarlar substansif rasyonelliğe sahipken hakem formal rasyonelliğe sahiptir. Hakem formal rasyonelliğin temsilidir. Hakeme dair tartışmaların çıkmasını ise formal rasyonellik ve substansif rasyonellik arasındaki çatışmadan çıktığını söyleyebiliriz. Kalberg'e göre (2010, s.1158) formal rasyonellik ve substansif rasyonellik arasındaki çatışma Batı'nın rasyonellik geçmişinin özetidir. Bu rasyonellik kişilerin kendi değerleri üzerinden oluşturdukları rasyonellik olarak yorumlandığından hakemin kararları taraflar arasında itilafa yol açmaktadır.

Modern otorite Weber'e göre, rasyonelliğe, hukukun tarafsız bir irade sergileme gücüne ve uzman bireyler veya görevlilerin üzerinde birleştikleri kurallara dayanır (Slattery, 2011). Böylelikle VAR bu görevi üstlenmiş, formal ve substansif otorite arasındaki uyumsuzluğu, çatışmayı gidererek 
tarafsızlığı sağlamak adına futbolda büyük bir adım atılmasını sağlamıştır. Bu bağlamda VAR'ın ortaya çıkış1, gelişimi ve fubola etkileri gelecek bölümde anlatılacaktır.

\section{Video Yardımcı Hakem Uygulaması (VAR)}

Portekiz-Şili maçında Pepe'nin attı̆̆ golün video hakem teknolojisi ile birlikte iptal edilmesi, video hakem teknolojisinin futbol hayatına girdiğinin ve futbola dair önemli bir karara imza atıldığının göstergesi oldu (Video hakemden ' 3 gol' kararı, Milliyet, 19.06.2017). Futbolda son yıllarda gördüğümüz VAR, video aracılığıyla yapılan hakemliği kapsamaktadır. Maç esnasında yakın mesafeden kayıt alınan ve oyunu görüntüleyen bu uygulama, futbol camiası tarafından büyük coşkuyla karşılanmıştır.

"Video Yardımcı Hakem sisteminin amacı tüm kararlarda \%100 doğruluk elde etmek değildir. VAR'ın genel felsefesi "minimum müdahale - maksimum yarar"dır. Her türlü kararı her zaman hakem verecektir. Hakemin kararl, yalnızca video incelemesi bariz bir hatayı gösteriyorsa değiştirilebilir” (TFF, Video Yardımcı Hakem Kitapçı̆̆ı). VAR'ın (veya başka bir maç görevlisinin) maçın gidişatına ve pozisyon durumlarına yönelik inceleme önermesi veya hakemin ciddi bir durumun 'gözden kaçtığından' şüphelenmesi durumunda VAR'a başvurulabilir. VAR sistemine başvuran hakem eliyle kare/TV işareti yaparak VAR ile şekillenen kararını uygulamaya koyabilir. VAR, maç sırasında her durumu diğer yardımcı hakemler gibi kontrol etmekte ve gerektiğinde maçın hakemini uyarmaktadır. Bu nedenle VAR her bir durumu/kararı otomatik olarak 'kontrol' edeceği için, antrenörlerin veya futbolcuların 'kontrol' veya 'inceleme' talep etmesine gerek yoktur (TFF, Video Yardımcı Hakem Kitapçığı).

VAR üzerine yazılmış bir adet akademik makale bulunmaktadır. (Engin \& Çelik, 2019) Bu sınırlı çalışmada, VAR deneyimi olan 5 adet hakemle yapılandırılmış görüşme formu üzerinden görüşmeler yapılmış ve bu veriler analiz edilmiştir. Yazarlar nihai sonuçları değerlendirmek konusunda çeşitli görüşlere başvumuşlar, genel bir değerlendirme ve kodlama konusunda eksik kalmışlardır. Bir ilk olması açısından ve hakemlerin görüşlerine değinmesi açısından çok değerlidir. İlgili makalede hakemlerin daha önceden belirttiğimiz sebeplerden ötürü bunu bir firsat olarak gördükleri açıktır. "Katılımcı-5: Ĕger karar verdiğimiz bir pozisyonda doğru açıda değilsek ve kararımızdan emin değilsek, adaleti sağlamak adına VAR sistemine gidebiliriz. Bu bizim için bir firsat." (Engin \& Çelik, 2019, s.60) "Katılımcı-2: Hakemlerin her pozisyonu görmesi imkânsızdır çünkü her zaman doğru açıya sahip olmak zor bir şeydir” (Engin \& Çelik, 2019, s.60).

Akademik olmamakla birlikte veri toplayan İngiliz ticari kuruluşu Good Form Group kaç kişiyle yaptıklarını açıklamasalar da yaptıkları taraftar araştırmasının sonuçlarında, büyük kararlar hakkında VAR öncesi \%96 oranında hakemlerin yanlış karar verdiklerini söylerlerken, VAR'ın taraftarlar üzerindeki etkisini açıklarken taraftarların \%47'sinin yanlış kararların üzerinde yarattıkları hüsranı engellediğini beyan etmişlerdir. (www.goodformgroup.co.uk/uk-football-fans-views-onthe-use-of-var/, 2020)

Türkiye Futbol Federasyonu'nun son yıllarda almış olduğu karara göre, VAR işareti yaparak hakemin kararına müdahale eden futbolcular, sarı kart cezası alacaktır. "Gözden kaçan herhangi bir şey VAR tarafindan zaten görüleceğinden, antrenörlerin veya oyuncuların inceleme talep etmeleri kesinlikle yasaktır" (TFF, Video Yardımcı Hakem Kitapçı̆̆ı). VAR'ın yapacağı uyarılar maçın seyrini değiştirebilir. Ancak son karar her zaman hakemdedir. Hakem isterse VAR sistemine göre hareket etmeyebilir. VAR hakeme sadece inceleme seçeneği sunabilir. Hakemin kararına müdahale etmez.

Bu konu ile ilgili yaptığım haber incelemeleri alt alta konulduğunda ve bütün halinde bakıldığında, konu önemli toplumsal bir olay olarak görülmelidir. Bugüne kadar yaşanan toplumsal olaylar şiddet içermeseler de, hakem ve hakem aramasını yapan bürokratik kurumlar yüzünden taraftarların birlik olup yürümeleri bu makalede bahsettiğimiz meselenin önemini ortaya 
koymaktadır. Öte yandan Tablo 1'de görüldüğü üzere hakeme karş1 olan tepkiler azalmamış ve değişmemiştir. Çünkü nihai karar verici halen daha VAR değil; hakemdir.

Tablo 1: Taraftarların Hakemi Protesto Yürüyüşleri

\begin{tabular}{ll}
\hline VAR'dan önce & \\
\hline Beşiktaş & 22.12 .2013 \\
Mersin İdman Yurdu & 14.12 .2014 \\
Samsunspor & 26.04 .2015 \\
Kayserispor & 08.10 .2015 \\
Fenerbahçe & 07.10 .2017 \\
VAR'dan sonra & \\
\hline Galatasaray & 12.11 .2018 \\
Erzurumspor & 05.02 .2019 \\
Trabzonspor & 09.11 .2019 \\
Fenerbahçe & 12.02 .2020 \\
Sivasspor & 10.02 .2020
\end{tabular}

Weber'in otorite tiplemeleri ile futbol hakeminin ilişkisini açıklayacak olursak; video yardımcı hakem protokolü yürürlüğe girmeden evvel hakemin karar yetkisi, edindiği bilgileri ve geleneksel sistemin kurallarını sahaya indirgemesiyle gerçekleşir. Hakemin kararlarını o anda doğrulayacak bir sistem bulunmamakta, hakem pozisyonlara ilişkin kararı kendi saha hakimiyeti üzerinden almaktadır. Bu karar, saha içerisinde o anda verilmektedir. Ayrıca verilen karara yönelik içinde bulunulan mekanın koşulları hakemin kararına, yasal otorite kullanımında olduğundan daha fazla etki eder. 'Hakemin ev sahipliği yapan takımın lehinde karar vermesi' durumunda olduğu gibi.

VAR sistemine geçişle aynı zamanda daha sistematik, daha denetlenebilir bir sisteme de geçilmiş olur. Video yardımcı hakem uygulamasının yürürlüğe girmesiyle, Weber'in rasyonel otoritesinde olduğu gibi iş bölümü gerçekleşmiş; video yardımcı hakemine de söz hakkı doğmuştur. VAR'ın gerekli gördüğü anlarda hakeme tavsiyelerde bulunması, formal otoritenin koltuğunu sarsar niteliktedir. Formal otorite sahibi bireyin kararları, sorgulanmaya müsait olmadan birebir kabul edilir. Hakemin bir pozisyona penaltı vermesine rağmen maçtan sonraki tekrarlarda penaltının geçersizliğinin ispat edilmesi ancak kararın değiştirilememesi gibi.

VAR sistemiyle, hakemin görüş alanı dışında gerçekleşen olaylar da birebir kayıt altına alındığından dolayı; hakemin maç esnasında VAR tarafindan uyarılabilmesi söz konusudur. Örneğin; 2018 Dünya Kupası'nda Peru'nun Danimarka ile karşı karşıya geldiği maçta, ilk yarının son saniyelerinde ceza alanında yaşanan bir pozisyonda rakip oyuncunun müdahalesiyle Perulu oyuncu Cueva yerde kalmıştı. Bu esnada hakem oyunu devam ettirirken VAR sistemi pozisyonun penaltı olduğuna karar vermiş̧ir. Bu kararın sonunda hakem de penaltı atışı kullanılmasında karar kılmıştır. Verilen örnekte olduğu gibi, rasyonel iş bölümünün bir örneği olan video hakem maça etki edebilir. VAR uygulaması futbola daha sistematik ve müdahaleye açı bir ortam sunmaktadır. Bu durum da yine Weber'in rasyonel-yasal otoritesine benzerlik gösterir. Daha az kuralcı, yanlışlanabilir, müdahale edilebilir ve yargilanabilir bir durum söz konusudur.

VAR'a rağmen nihai kararın yine hakemde toplanması formal rasyonelliktir. Hakemin kararı ne kadar müdahaleye ve tavsiyeye açık olsa da hakem VAR'1 dinlemeyebilir. Karar verme yetkisi, maçın hakemini hiyerarşi piramidinin en üst bölgesinde bulundurur. Şüphesiz bu durum teknolojinin daha da gelişmesi ile birlikte son bulabilir. Yukarıda bahsettiğimiz araştırmada bir hakem şunu belirtmektedir. Katılımcı-1 "Teknoloji bu saatten sonra artık bizler için hayal gücümüzün ulaşttğı nokta. Belki de ileride maçlar hakemsiz bile yürütülebilir" (Engin \& Çelik, 2019, s.61). Post-modern düşüncenin "biri bizi gözetliyor" şeklinde ifade ettiği durum futbol oyununun içerisinde "hakem" 
figürü üzerinden kendisini göstermiştir. Bu anlamda bir parça post-modern teorilerde VAR'a ve hakeme dair etkileşim kurabileceğimiz görüşleri aramak uygun olacaktır.

Weber çok güçlü bir sosyoloji teorisyeni olmasına karşın, günümüz toplumu hızla değişmekte bu da bazı teorileri gözden geçirmemize ve yeni teorileri ve toplumun değişen dinamikleri ile birlikte açıklamamıza gerek olduğunu göstermektedir. Günümüz dünyasında her yer kameralarla sarılmış, futbol izleyicileri ile medya arasındaki alışveriş milayar dolarlarla ifade edilir hale gelmiştir. $\mathrm{Bu}$ anlamda Weber sonrası VAR üzerine bizlere faydalı olabilecek post-modern teorilere göz atmamız gerekmektedir.

\section{Post-Modern Bakış: Fouccault ve Deleuze}

VAR futbol müsabakasını izleyen formal gözlerden oluşurken, VAR'1 kaçınılmaz kılan ise Baudrillardçı anlamda bir hiper-gerçeklik figürü olarak televizyon ve futbol maçlarının canlı yayınlarıdır. Onlarca kamera ve yüksek çözünürlükle (4K) aktarılan maçlar ve maçlarda oluşan hakemin hızla karar vermek zorunda kaldığı pozisyonlar, televizyon başındaki izleyiciler ve taraftarlar tarafindan daha ayrıntılı, tekrar tekrar ve farklı açılardan izlenebilmesiyle birlikte, hakemin formal rasyonel kararı ve taraftarların substansif rasyonel kararları arasındaki çelişkiyi doğurmuştur. $\mathrm{Bu}$ anlamda hakem tam olarak panoptikon baskısı altında kalmıştır.

Panoptikon kavramı modern sosyolog ve filozof olan Foucault tarafından ortaya atılmış bir kavramdır. Modern iktidarın işleyişini, yapısını anlatmak için panoptikon metaforunu kullanır. Panoptikon, Jeremy Bentham'ın 1785 yılında tasarlamış olduğu hapishane inşa modelidir. Panoptikon, içerisinde hücre barındıran halka şeklinde bir yapıya sahiptir. Yapının ortasında hücreleri kolaylıkla gözlemleyen bir gözlem kulesi mevcuttur. Hücrelerin yapısı, gözlem kulesinden izlenmesine müsait bir yapıdadır. Bu hücrelere içeriden ve dışarıdan iki pencere takılmıştır. İlki, hücrenin açık seçik izlenmesini sağlarken; ikincisi mahkumun saklanması durumunda mahkumun gölgesini ortaya çıkaracak ışı̆̆ın dışardan geldiği penceredir. Aynı zamanda içeriden tüm 1şıklar da mahkumun kolaylıkla gözlenmesini/izlenmesini sağlamaktadırlar. Nitekim mahkumlar da sürekli izlenmiş olmanın verdiği rahatsızlıkla, kendilerini gözleyenin gözünden görmeye başlayacaklardır; bu beklenti doğrultusunda hareket etmeye başlayacaklardır. Otorite yani gözlemleyen orada olsa da olmasa da mahkum, otorite oradaymış gibi davranmaya devam edecektir (Foucault, 2006, s.96).

Panoptikon kavramından hareketle gözetlenen hakemin gözetlenmediği durumlarda bile üzerindeki bask1 ve otorite sebebiyle nas1l kararlar vereceği üzerine henüz literatürde herhangi bir çalışma yoktur -ki buna VAR da dahildir-. Taraftarlar tarafından direkt gözetlenen hakemler verdikleri kararlar üzerine yapılmış çalışmalarda hakemin tarafsız olması beklenmesine rağmen ev sahibi lehine kararlar alma eğiliminde olduğu gözlemlenmiştir. Boyko ve Satman'nın araştırmalarına hakem ile ilgili bölümde değinmiştik. Aynı bağlamda Courneya ve Carron (1992), hakemlerin ev sahibi takımların lehine kararlar verdiklerini araştırmalarında kanıtlamışlardır. Bu araştırma bu alanda başat niteliği taşımış, ardından benzer arştırmalar yapılmıştır. Buradaki araştırmalar sadece ev sahibi lehine değil; aynı zamanda rakip takımın cezalardan nasibini daha fazla aldığ kanıtlanmıştır. Ev sahibi olmayan takıma verilen sarı ve kırmızı kart cezalarının daha fazla olduğu kanıtlanmıştır (Dawson \& Dobson, 2009; Dawson ve arkadaşları, 2007). Dohmhein ise Alman en üst ligi olan Bundesliga maçlarını inceleyerek çok daha ilginç bir sonuç bulmuştur. Bundesliga'nın incelenmesi seyirci açısından önemlidir çünkü statlar \%90 doluluk oranına ulaşırlar. Bundesliga'da eğer ev sahibi takım gerideyse hakem maçı özellikle ikinci yarıda daha çok durdurarak ev sahibi takım lehine kararlar vermiştir. (Dohmen, 2008, s.8) Ayrıca araştırmalarda ev sahibi takım yenik durumda ise kendisine maç sonunda topun oyunda olmadığ sürenin daha fazla verildiği kanıtlanmıştır. (Sutter \& Kocher, 2004)

Hakemin kararlarının etkilenmesi konusu Türkiye'nin sıcak konusu olarak gündemdeki yerini devamlı korumaktadır. Konu ile ilgili olarak İrem Kavasoğlu tarafından yazılmış ve kitaplaşmış bir doktora tezi bulunmaktadır. "Kayırmacılık Temelli İlişkilerin Futboldaki 
Görün̈̈тӥ̈"(2019) adlı tezde 12 eski hakem ile nitel görüşmeler yapılarak hakemlerin kayırmacılık yapıp yapmadıkları ortaya çıkarılmaya çalışılmıştır. Araştırmanın sonucu olarak, “... Oyunun yönetici konumunda olan hakemlerin ve hakemlerin yöneticisi konumunda olan TFF ve MHK'nin bilinçli ya da bilinçsiz olarak ve zaman zaman kayırmacılığın eyleyicisi konumunda olduklarına işaret etmektedir" (Kavasoğlu \& Yener, 2018, s. 2524).

$\mathrm{Bu}$ etki panoptikon etkisi gibi gözükmekle birlikte, bu makaleyi ilgilendiren yanı, VAR sistemi ve dönüşen toplum ile ilgili bahsedeceğimiz bir sonraki görüşün yani disiplin toplumundan denetim toplumuna geçişin önemini anlatması açısından göze çarpıcıdır. Kavasoğlu'nun tezinde, hakemlerin anlatıları, Süper Lig'e göre daha az göz önünde olması, televizyonlarda daha az yer alması ve daha az denetlenmesi gibi nedenlerle alt liglerde kayırmac1 edimlerin daha fazla yaşandığına işaret etmektedir. Kod ismi Yılmaz olan hakem "Yukarıdaki maçlar gözünde bulunduğu için, her türlü maçlar yayıncı kuruluş tarafindan yayınlanıp bittiğinde herkes izliyor ama alt tarafta, ben de boş olduğum zamanlarda gidiyorum, üçüncü lig ikinci lig maçlarına, resmen alt tarafta katliam var." (Kavasoğlu\&Yener, 2018, s. 2526) şeklindeki sözleri, alt liglerde kayırma pratiklerinin daha yoğun olduğunu ortaya koymaktadır. Yine kod ismi Faik olan hakem ise, özellikle Süper Lig'de pek çok farklı açıdan çekim yapan kameraların oyuna şeffaflık kazandırdığına dikkat çekmiştir.

Bu da bizleri Fouccault'u çok iyi okumuş bir sosyal teorisyen olan Fransız filozof ve sosyolog Gilles Deleuze'e getirir. Deleuze'e göre disiplin toplumları denetim toplumları ile yer değiştirmeye başlamıştır (Deleuze, 1992, s.4). "Eski parasal köstebek, yılan ile yer değiştirmiş bir hayvandan diğerine geçiş yaşanmıştır. Bu yaşayış tarzımızı, diğer insanlarla olan ilişskilerimizde de değiş̧ime yol açmış̧ır. Disiplin toplumunun insanı sürekliliği olmayan enerjinin üreticisi gibidir fakat denetim (kontrol) dalgall, devamlı ăgda ve yörüngede kalandır. Eski spor, surf yapmak ile yer değiştirmiştir" (Deleuze, 1992, s.6).

Günümüz futbol izleyicisi sadece statlarda futbolu izleyen kişilerden oluşmaz, en çok televizyonları başında futbol izleyen kişilerden oluşur; hatta buradan gelen gelirler kulüplerin genel gelirinin en yüksek kalemini oluşturur. Barcelona Futbol Kulübü'nün gelirlerinin \%34'ü (ki buna reklam gelirleri dahil değildir) yayın gelirlerinden gelmektedir. (fcbarcelona.com) Bu da futbol izleyicilerini hiper-gerçek ve yörüngede yapar. Sürekli olarak hakemin karar verdiği pozisyonları en ince detayına kadar çok yüksek bir hızla öğrenebilmekte ve substansif rasyonalitesi ile yorumlayabilmektedir. Bu yalnız başına futbolcular ile birlikte ter döken, poziyonları da bir yandan hızlı bir kesinlikle yorumlamaya çalışan kendi üst brokrasisi tarafından baskı altında bulunan hakemin elini savunmasız bırakmıştır. Bu anlamda VAR denetimine geçiş, kaçınılmaz hale gelmiştir.

Şüphesiz VAR'ın gelmesiyle birlikte tüm sorunların çözüldüğünden bahsedemeyiz. VAR sisteminin oturması ve VAR sistemine başvurma konusundaki takdir, hala daha orta hakemindir. Bu otomasyon süreci şüphesiz her formal, bürokratik yapının değişimi gibi zaman alacaktır. Halihazırda eski hakemler yeni sistemi kullanmaktadırlar. Fakat yeni nesil VAR hakemleri ve bazı denetleyici düzenlemeler ile televizyonu başında taraftarın gördüğü ile sahada gerçekleşen arasındaki adaletsizlik zamanla kapanacaktır.

\section{Tartışma ve Sonuç}

Bir futbol maçında, o maçın otoritesi hakemde toplanmaktadır. Hakem oyuna ilişkin her türlü kararı verebilen ve oyunu yöneten kişidir. Max Weber'in yasal-ussal otoritenin altında formal rasyonellik olarak tarif ettiği gücün vücut bulmuş halidir. Kararları kesindir ve tartışmaya açık değildir. Video yardımcı hakem uygulaması ile formal rasyonellik sahibi konumundaki hakemin kararları, substansif rasyonalite sahibi taraftar kararlarına dönüşmesi beklenir. Futbolun VAR sistemini yürürlüğe koymasıyla; daha kesin, daha rasyonel ve daha yanlışlanamaz kararlar alınmaya başlamıştır. Video yardımcı hakem oyuna dahil olduğunda hakemi, pozisyonlara yönelik uyarır ve bu durum hakemin kararına büyük etki etmesi beklenmektedir. Lakin henüz bunun gerçekleştiği görülmemektedir. 
VAR'ın yürürlüğe girmesiyle, hakemin formal rasyonelliği tam olarak obejektifliğe dönüştü denilemez. Çünkü son karar, daima oyunu yöneten hakeme aittir. Weber'in yasal-rasyonel otoritesi bir kişide değil, kurallarda toplanır. Yasalar en üstün güçtür ve yasaların yönettiği bir sistem söz konusudur. VAR müdahalesinin sorgulanamaz ve kesin kabul edildiği ve hakemi uyardığında kesin olarak VAR'a göre karar alındığı takdirde ancak o zaman oyunda formal rasyonellliğin tam olarak uygulandığı yani hakemi denetleyen hakemin üstünde bir kuraldan söz edilebilir. Yakın gelecekte ortaya çıkabilecek dahi olsa, şu an için böyle bir durum tam olarak söz konusu değildir.

Hakem ve çevresindeki bürokrasi hali hazırda konumunu terk etmeye hazır değil gibi gözükmektedir. Teknolojinin daha hakim pozisyona geçmesi ve bürokratik yapıların ağır hareket etmesi ile problem yakın gelecekte çözülecek gibi gözükmektedir. Tabi ki taraftarların makale boyunca bahsetmiş olduğumuz baskıları, bunun çözülmesinde en büyük rolü oluşturmaktadır. VAR ile büyük bir adım atılmıştır fakat tam olarak aygıtları ile birlikte istenilen yönde işlememektedir.

Bir eleştiri olarak, futbolun doğasında belirsizlik olması gerektiği savunulabilir. VAR sisteminin oyunu sürekli durdurarak hakemin sisteme başvurmasının sıkıcı ve duraksayan bir oyun oluşturması da işin diğer bir tarafi gibi gözükmektedir. VAR her ne kadar rasyonel temeller ve adalet getirse de spor ekonomisinde kullanılan "sonucun belirsizliği" (Sloane, 2006) kavramının oyunu daha güzel kıldığ 1 savunulmaktadır. Bunun yanı sıra Haugen (2019)'a göre ise İngiliz Futbol Ligi’nde belirsizliğin giderek azaldığı ve kötü takımların iyi takımları yenme olasılığının giderek düştüğü ve bunun futbolun doğasına zarar vereceği bir başka görüştür.

VAR teknolojisi ile birlikte daha şeffaf hakem ve taraftar arasındaki çekişmenin azaldığı bir yönetim şekli hedeflenmekle birlikte, araştırmalar bizlere ilginç sonuçlar da vermektedir. Yukarıda bahsetmiş olduğumuz Good Form Group araştırmasında ortaya çıkan son derece ilginç bir sonuç daha vardır. Bu da taraftarların \%54'ünün hakem kararları üzerine tartışmaktan zevk almalarıdır. Bu son derece ilginç, üzerine düşünülmesi gereken bir sonuçtur. En nihayetinde futbol eğlence sektörünün bir parçası konumundadır. Eğlence çok zor tanımlanan, içerisinde çekişme ve tartışmayı da barındıran çok geniş bir kavram olarak hayatımızdadır.

\section{Kaynakça}

Afacan, E., Bal, H., Gümüşdağ, H., Çobanoğlu, G. (2015). Sosyolojik Açıdan Futbol ve Profesyonellik. Hitit Üniversitesi Sosyal Bilimler Enstitüsü Dergisi, 7(2), 525-542. https://doi.org/10.17218/husbed.93816

Andersen, T.E., Engebretsen, L., Bahr R. (2004). Rule Violations as a Cause of Injuries in Male Norwegian Professional Football. The American Journal of Sports Medicine, 32 (1), 62-88. https://doi.org/10.1177\%2F0363546503261412

Boyko, R., Boyko, A., Boyko, M. (2007). Referee bias contributes to home advantage in English Premiership football. Journal of sports sciences, 25, 1185-94. https://doi.org/10.1080/02640410601038576

Can, İ., Ersoy, K., Bayrakdaroğlu, S. (2017). Gümüşhane İl Aday Futbol Hakemlerinin Bazı Performans Parametrelerinin İncelenmesi. İnönü Üniversitesi Beden Eğitimi ve Spor Bilimleri Dergisi, 3(3), 23-40.

Cel, A (1994). Hakemlik Psikolojisi. Futbol Bilim ve Teknoloji Dergisi, çeviren: Kin A, 1, 21-23, Ankara.

Courneya K. S., Carron, Albert V. (1992). The home advantage in sport competitions: A literature review. Journal of Sport and Exercise Psychology, 14, 13-27. https://doi.org/10.1123/jsep.14.1.13 
Çakmak, M., İşlek, M., Keskin, U. (2017). Türk Futbol Kültürünün Küreselleşme Kavram ve Süreçleri Bağlamında Değerlendirilmesi. Karamanoğlu Mehmetbey Üniversitesi Sosyal ve $\begin{array}{llll}\text { Ekonomik Araştırmalar } & \text { Dergisi, } & 19(33), & 125-133 .\end{array}$ https://doi.org/10.18493/kmusekad.400615

Dawson, P., Dobson, S. (2009). The influence of social pressures and nationalities on individual decisions: evidence from the behaviour of referees. Journal of Economic Psychology, 25, 461-469. https://doi.org/10.1016/j.joep.2009.06.001

Dohmen, T.J. (2008). The Influence Of Social Forces: Evidence From The Behavior Of Football Referees. Economic Inquiry, 46, 411- 424. https://doi.org/10.1111/j.14657295.2007.00112.x

Engin, S., Çelik, V. (2019). VAR'lığın YETER! Hakemlerin Gözünden Video Yardımcı Hakem Sistemi. International Journal of Sport Culture and Science, 7(2), 53-68.

Eşki, H. (2010). Bugünü Anlamak İçin Max Weber'i Yeniden Okumak. ZKÜ Sosyal Bilimler Dergisi, 6(11), 187-198.

Foucault, M. (2006) Hapishanenin Doğuşu. (Kılıçbay M.A., Çev.) İmge Yayınları, 8. Baskı, İstanbul.

Frank, M. G., Gilovich, T. (1988). The dark side of self- and social perception: Black uniforms and aggression in professional sports. Journal of Personality and Social Psychology, 54(1), 7485. https://doi.org/10.1037/0022-3514.54.1.74

Hürmüz, P. (2016). 6222 Sayll Sporda Şiddet ve Düzensizliğin Önlenmesine Dair Kanun Yasak Fiiller ve Ceza Hükümleri Yargıtay Yorumu. Adalet Yayınevi, 1. Baskı, Ankara.

Kavasoğlu, İ. (2019) Kayırmacılık Temelli İlişkilerin Futboldaki Görünümü. Gazi Kitabevi, Ankara.

Kavasoğlu, İ., Yenel, İ.F. (2018). Hakemlerin gözünden futbolda kayırmac1lık. Journal of Human Sciences, 15(4), 2509-2532.

Kuper, S. (1996) Futbol Asla Sadece Futbol Değildir. (Gürtunca S., Çev.) Sabah Kitapları Yayınları, İstanbul.

Lawrence C. B., Charlotte B. B. (2001) Encyclopedia of Ethics. Routledge, 2. Bask1, Londra.

Ok, A. (2020). Max Weber'de Otorite ve Meşruiyet Tipolojisi. Avrasya Sosyal ve Ekonomi Araştırmaları Dergisi, 4(8), 42-54.

Önür, N. (2015). Profesyonel Hakemlik Bilgi Birikimi Geliştirme Sürecinde Futbol Hakemlerinin Geleneksel ve Sosyal Medya Kullanım Pratikleri. E-journal of internmedia, vol.2, 392-410.

Özocak, G. (2018). Spor Faaliyetleri Sırasında İşlenen Kasten Yaralama Suçu. Suç Ve Ceza, Sayı 3 , 81-95.

Özdemir, G. (2014). Weberyan Anlamda Türklerde Otorite ve Meşruiyet İlişkisi (15.yüzy1l Osmanlı Dönemine Kadar). Akademik Incelemeler Dergisi, 9(2), 69-90. https://doi.org/10.17550/aid.72794

Satman, C. (2014). Futbol Maçlarındaki Seyirci Topluluklarının Sesinin, Hakemlerin Kararları Üzerindeki Etkisi. SPORMETRE Beden Eğitimi ve Spor Bilimleri Dergisi, 12 (2) , 147-154. https://doi.org/10.1501/Sporm_0000000263

Sloane, P.J. (2006). Rottenberg and the Economics of Sport after 50 Years: An Evaluation. IZA Discussion Paper No. 2175, Institute for the Study of Labor, Bonn.

Slattery, M. (2008). Sosyolojide Temel Fikirler. (Tatlıcan Ü. \& Demiriz G., Yayına Haz.) Sentez Yayıncılık, 1. Baskı, Bursa. 
Sutter, M., Kocher, M. (2004). Favouritism of agents: The case of referees home bias. Journal of Economic Psychology, 25, 461-469. https://doi.org/10.1016/S0167-4870(03)00013-8

Szelényi, I. (2011). Social Theory [MOOC]. Yale Online Courses. https://oyc.yale.edu/sociology/socy-151/lecture-18

Şen, H. (2013). Futbolun Değişen Yapısı Üzerine Sosyolojik Bir Analiz. Yakın Doğu Üniversitesi Sosyal Bilimler Dergisi, 6(1), 88-105.

Türkiye Futbol Federasyonu. (2018). Video Yardımcı Hakem Kitapçı̆̆ı. [Broşür] https://www.tff.org/Resources/TFF/Images/MHK/VAR.pdf

Uzdu, H. (2016). Max Weber'in Otorite Tipolojileri Bağlamında "Son İmparator", "Gandi" ve "Lincoln" Filmlerine Sosyolojik Bir Bakış Denemesi. Celal Bayar Üniversitesi Sosyal Bilimler Dergisi, 14(3), 67-87. https://doi.org/10.18026/cbusos.36767

Uzunoğlu, Ö.F. (2008). Türk Futbol Hakemlerinin Karar Verme Stillerinin Klasmanlarına ve Bazı Değişkenlere Göre İncelenmesi [Basılmamış doktora tezi]. Selçuk Üniversitesi Sağlık Bilimleri Enstitüsü, Konya.

Weber, M., Parsons, T., \& Tawney, R. H. (1930). The Protestant ethic and the spirit of capitalism. George Allen \& Unwin Ltd., Museum Street, London.

Weber, M. (1946). The Social Psychology of the World Religions. In Editors Gerth, H. \& Mills, W. Essays. (pp. 267-301). London: Routledge. https://doi.org/10.4324/9780203452196

Weber, M. (1978). Economy and Society: An Outline of Interpretive Sociology (Roth G. \& Wittich C. Eds.). University of California Press.

Wilson, J. O. S., Dawson, P., Dobson, S., \& Goddard, J. (2007). Are football referees really biased and inconsistent?: evidence on the incidence of disciplinary sanction in the English Premier League. Journal of the Royal Statistical Society: Series A (Statistics in Society), 170(1), 231 250. https://doi.org/10.1111/j.1467-985X.2006.00451.x 